\title{
Synthesis and characterization of nanocrystalline barium strontium titanate powder by a modified sol-gel processing
}

\author{
M.E. AZIM ARAGHI ${ }^{1}$, N. SHABAN ${ }^{1 *}$, M. BAHAR ${ }^{2}$ \\ ${ }^{1}$ Department of Physics, Kharazmi University, Tehran, Iran \\ ${ }^{2}$ Department of Physics, Islamic Azad University North Tehran Branch, Tehran, Iran
}

In this research work, nanocrystalline $\mathrm{BST}\left(\mathrm{Ba}_{0.6} \mathrm{Sr}_{0.4} \mathrm{TiO}_{3}\right)$ powders were synthesized through a modified sol-gel process, using barium acetate, strontium acetate and titanium isopropoxide as the precursors. In this process, stoichiometric proportions of barium acetate and strontium acetate were dissolved in acetic acid and titanium (IV) isopropoxide was added to form BST gel. The as-formed gel was dried at $200{ }^{\circ} \mathrm{C}$ and then calcined in the temperature range of 600 to $850{ }^{\circ} \mathrm{C}$ for crystallization. The samples were characterized by infrared spectroscopy method (FT-IR), X-ray diffraction technique (XRD) and field emission scanning electron microscope (FESEM) and energy dispersive X-ray spectroscopy. EDS analysis of these samples confirmed the formation of the final phase with the special stoichiometry. The formation of a cubic perovskite crystalline phase with nanoscale dimension was detected using the mentioned techniques. The results showed that the obtained crystallite sizes were 33 and $37 \mathrm{~nm}$ for BST powder calcined at 750 and $850{ }^{\circ} \mathrm{C}$, respectively.

Keywords: barium-strontium titanate; nanocrystalline; sol-gel process

(C) Wroclaw University of Technology.

\section{Introduction}

Barium strontium titanate (BST) is a ternary ceramic compound with the stoichiometric formula $\left(\mathrm{Ba}_{\mathrm{x}} \mathrm{Sr}_{1-\mathrm{x}} \mathrm{TiO}_{3}\right)$. BST is a continuous solid solution containing $\mathrm{BaTiO}_{3}$ and $\mathrm{SrTiO}_{3}$ over the entire composition range. The solid solution of BST has emerged as a strong candidate material for such applications. It is well-known that BST has a variety of electronic applications in multilayer and voltage-tunable capacitors, dynamic random access memories (DRAM), microwave phase shifters, tunable filters, oscillators, uncooled infrared sensors, etc. due to the high dielectric constant, nonlinear variation of dielectric constant with the electric field, ferroelectricity, pyroelectric properties and so on. These aforementioned properties strongly depend on the composition and characteristics of raw materials [1, 2]. In this research $\mathrm{Ba}_{0.6} \mathrm{Sr}_{0.4} \mathrm{TiO}_{3}$ was chosen as a basic composition because of its good combination of low $\mathrm{T}_{\mathrm{C}}$, high dielectric constant, relatively low loss tangent and good tenability $[2,3]$.

\footnotetext{
*E-mail: n.shaban2014@gmail.com
}

Various preparation methods for BST have been investigated, such as solid-state reaction [4], sol-gel [5-7], hydrothermal [8, 9], spray pyrolysis [10], combustion synthesis [11], and chemical co-precipitation methods [12]. Furthermore, other innovative methods, such as pulsed laser deposition (PLD) [13], R.F. sputtering [14], chemical vapor deposition (CVD), electrochemical [15], electrostatic spray assisted vapor deposition (ESAVD) [16] have been used to synthesize BST powders. Compared with other methods, solgel process, because of its numerous advantages in producing barium-strontium titanate ceramics, has received a strong attention among researchers. Among these advantages, low temperature of this process, possibility for obtaining nanostructures, easy control of microstructure and crystallization rate of the final product, lower pollution and low cost of operation can be noted [17, 18]. In this research, we aimed to synthesize nanocrystalline BST powders via sol-gel process because of its numerous advantages and potential applications of resulted products.

In order to evaluate the functional groups in prepared samples of BST powders, IR spectra of 
the xerogel and nanocrystalline powders were measured. The structure and phase identification were evaluated by XRD. The FESEM of barium strontium titanate (BST) revealed the presence of the nanophase in the prepared samples. This paper presents a detailed description of our synthesis process and characterization activities.

\section{Experimental}

\subsection{Powder synthesis}

The $\mathrm{Ba}_{06} \mathrm{Sr}_{0.4} \mathrm{TiO}_{3}$ nanopowder was synthesized using barium acetate (ACS reagent grade, $99 \%$, Merck, Germany), strontium acetate (ACS reagent grade, $99.9 \%$, Sigma Aldrich, USA) and titanium (IV) isopropoxide (ACS reagent grade, 99.9\%, Sigma Aldrich, USA) as precursors for barium, strontium and titanium, respectively. Acetic acid (glacial, 99 to $100 \%$ EMPLURA, Merck, Germany) was used as a solvent and ethanol $(99+\%$, Merck, Germany) was used to stabilize titanium (IV) isopropoxide. Stoichiometric proportions of barium acetate $(0.04 \mathrm{~mol})$ and strontium acetate $(0.026 \mathrm{~mol})$ powders were dissolved in 10 and $12 \mathrm{~mL}$ of heated glacial acetic acid, respectively, by continuous magnetic stirring at $300 \mathrm{rpm}$ for $30 \mathrm{~min}$. The two solutions were then mixed and stirred at $300 \mathrm{rpm}$ for $30 \mathrm{~min}$. Ethanol ( 2 to $5 \mathrm{~mL}$ ) was added into titanium (IV) isopropoxide $(0.066 \mathrm{~mol})$ to form a separate solution at room temperature. The $\mathrm{Ba}-\mathrm{Sr}$ solution was added to the as prepared Ti solution, in drops, with the help of a burette. $\mathrm{pH}$ of the solution was maintained in the range of 3.5 to 5 by adding buffering agents. Refluxing resulted in the formation of a thick white colored gel. The prepared gel was cooled to $5{ }^{\circ} \mathrm{C}$, deionized water was added to it and the solution was stirred magnetically for $60 \mathrm{~min}$. The solution was then dried at $100{ }^{\circ} \mathrm{C}$ and then heated to $200{ }^{\circ} \mathrm{C}$ for $2 \mathrm{~h}$ to separate the water completely, which resulted in the formation of amorphous $\mathrm{Ba}_{0.6} \mathrm{Sr}_{0.4} \mathrm{TiO}_{3}$ powder. The amorphous powder was then calcined at 600,750 and $850{ }^{\circ} \mathrm{C}$, separately, in a muffle furnace for crystallization. Fig. 1 presents a schematic of the process showing synthesis of nanocrystalline BST powder.

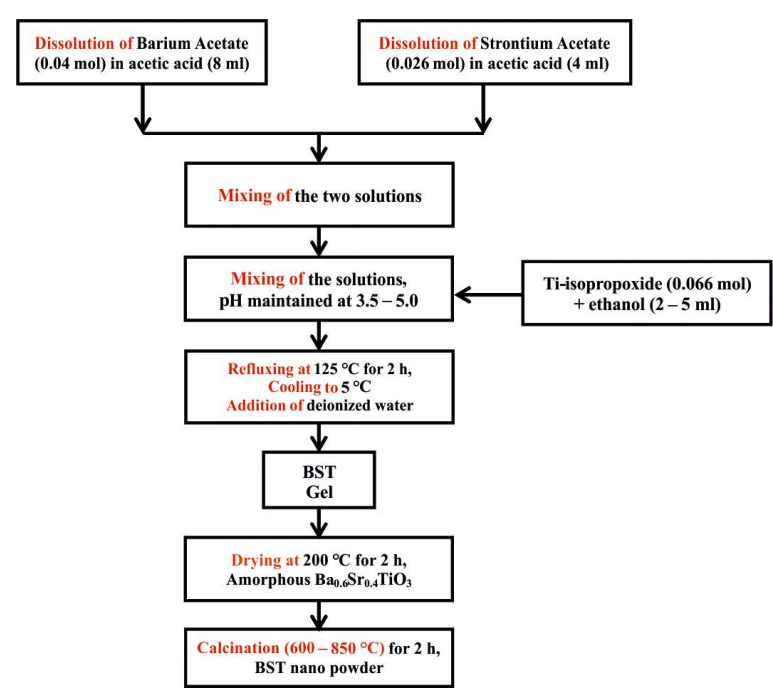

Fig. 1. Schematic detailing the synthesis of nanocrystalline BST powder.

\subsection{Characterization of BST nanopowder}

The phases of the obtained samples were characterized by X-ray diffraction (XRD) (Philips Xray diffractometer, $40 \mathrm{kV}, 40 \mathrm{~mA}$ ) in a wide range of Bragg's angle of $10^{\circ}$ to $85^{\circ}$ using $\mathrm{CuK} \alpha$ $(1.5406 \AA)$ radiation with a step size of 0.02 at room temperature. Microstructure was studied with a field emission scanning electron microscope (Mira 3-XMU). The chemical compositions of the samples were characterized by energy dispersive X-ray spectroscopy (EDS) (EDS microanalyzer in FESEM, Mira 3-XMU). Also, IR spectra of the xerogel and calcined powder were recorded with an FT-IR spectrometer (Bruker Vector 33) in the range of 400 to $4000 \mathrm{~cm}^{-1}$.

\section{Results and discussion}

\subsection{FT-IR analysis}

Fig. 2 shows the IR spectrum of the xerogel dried at $200{ }^{\circ} \mathrm{C}$ for $2 \mathrm{~h}$. The spectrum shows the presence of broad bands centered at $3380 \mathrm{~cm}^{-1}$ (water stretching vibrations) [19], $2996 \mathrm{~cm}^{-1}$ (C-H stretching modes) $[20,21], 2335 \mathrm{~cm}^{-1}$ $(\mathrm{C}=\mathrm{O}$ stretching modes $), 1715,1560 \mathrm{~cm}^{-1}$ (acetate groups), $1423 \mathrm{~cm}^{-1}$ (Ba-Ti-O bonds) [22], $1340 \mathrm{~cm}^{-1}(\mathrm{O}-\mathrm{H}$ deformations of primary 
alcohols), $1055 \mathrm{~cm}^{-1}(\mathrm{C}-\mathrm{O}$ stretching vibration of primary alcohols) [21], $936 \mathrm{~cm}^{-1}(\mathrm{O}-\mathrm{Ti}-\mathrm{O}$ stretching modes) [23], $658 \mathrm{~cm}^{-1}$ (Ti-O bending modes) $[17,23]$.

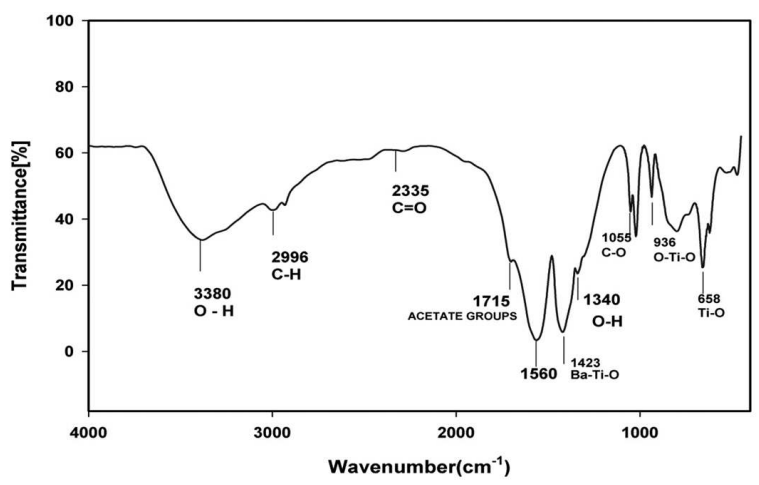

Fig. 2. FT-IR spectra of the xerogel.

Fig. 3 shows the IR spectra of BST powder calcined at $750{ }^{\circ} \mathrm{C}$ for $2 \mathrm{~h}$ and at $850{ }^{\circ} \mathrm{C}$ for $4 \mathrm{~h}$, respectively. The broad band at $3422 \mathrm{~cm}^{-1}$ is related to $\mathrm{O}-\mathrm{H}$ stretching modes of absorbed water by $\mathrm{KBr}$ pellets that were used for FT-IR spectroscopy [22]. The peaks corresponding to barium carbonate are evident at 1630, 1427, 850 and $580 \mathrm{~cm}^{-1}$ [24]. The absorption band at $1427 \mathrm{~cm}^{-1}$ can be interpreted as $\mathrm{C}=\mathrm{O}$ vibration due to extremely small unavoidable traces of carbonate. It can be seen that as the temperature increases, the amount of carbonates formed decreases. Hence, the result shows that the nanopowders obtained at $800^{\circ} \mathrm{C}$ are more pure than those obtained at $750{ }^{\circ} \mathrm{C}$, however high calcination temperature causes particle growth. Furthermore, the absorption band at $611 \mathrm{~cm}^{-1}$ is assigned to specific vibrations of Ti-O bonds [25]. As can be seen, the value of absorption at $611 \mathrm{~cm}^{-1}$ (Ti-O bonds) for BST powder calcined at $850{ }^{\circ} \mathrm{C}$ is higher than that of BST powder calcined at $750{ }^{\circ} \mathrm{C}$. This may be due to the purity, crystallinity and particle size of BST powder calcined at $850{ }^{\circ} \mathrm{C}$.

\subsection{Phase analysis of BST nanopowder}

Fig. 4 shows the XRD patterns of the powders calcined in air at 600 and $750{ }^{\circ} \mathrm{C}$ for $2 \mathrm{~h}$ and $850{ }^{\circ} \mathrm{C}$ for $4 \mathrm{~h}$, separately. It is observed that the peaks obtained at $600{ }^{\circ} \mathrm{C}$ are not sharp indicating that the particles are not fully crystallized. Thermal heat

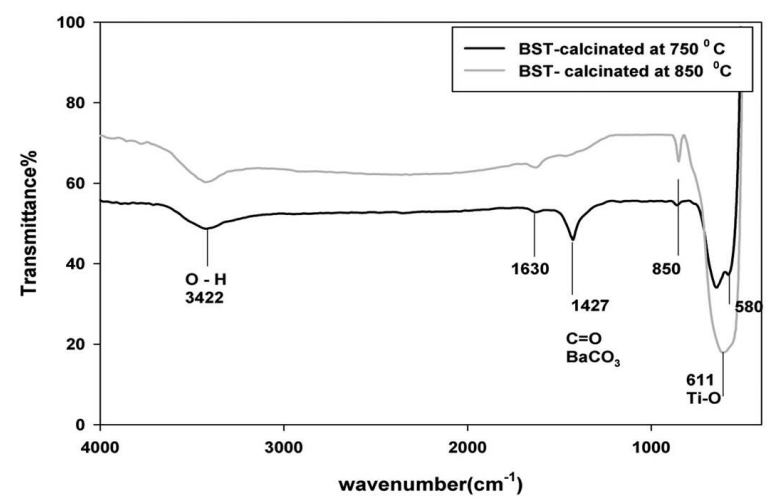

Fig. 3. FT-IR spectra of BST powder calcined at 750 and $850^{\circ} \mathrm{C}$.

treatment with appropriate time and temperature can cause the amorphous phase to crystallize because the amorphous phase is a thermodynamically metastable state. This is what we observed, when the calcination temperature was raised from 600 to $750{ }^{\circ} \mathrm{C}$ and $850{ }^{\circ} \mathrm{C}$. It can be seen that at $600{ }^{\circ} \mathrm{C}$, a weak line occurs at 24.2 which corresponds to the residual carbonates phase such as $\mathrm{BaCO}_{3}, \mathrm{SrCO}_{3}$ and $(\mathrm{Ba}, \mathrm{Sr}) \mathrm{CO}_{3}[19]$. At higher temperatures these peaks disappear and a pure BST phase is identified at $750{ }^{\circ} \mathrm{C}$ and $850{ }^{\circ} \mathrm{C}$. This indicates that as the temperature increases, the residual carbonates decompose. This can be confirmed by FT-IR analyses of BST powders calcined at $750{ }^{\circ} \mathrm{C}$ and $850{ }^{\circ} \mathrm{C}$. As seen in Fig. 4, the peaks observed for the powder calcined at $750{ }^{\circ} \mathrm{C}$ are sharp, revealing that the powder is fully transformed to a crystalline state at this temperature. In all three temperatures of calcination, the predominant phase is $\mathrm{Ba}_{0.6} \mathrm{Sr}_{0.4} \mathrm{TiO}_{3}$. The peaks of the prepared BST powders were identified using PDF Card No. 00-034-0411.

The XRD patterns of the prepared samples are in good agreement with the cubic BST phase (PDF Card No. 00-034-0411) as shown in Fig. 4. The crystallite size (d) is determined from the Scherrer's equation:

$$
\langle d\rangle=K \lambda / \beta \cos \theta
$$

where $\mathrm{K}$ is the Scherer constant, in the present case $\mathrm{K}=0.9, \lambda$ is the wavelength and $\beta$ is the full width (in radians) of the peak at half maximum (FWHM). 
Table 1. The Crystallographic parameters used for the XRD pattern fitting for BST60/40 ceramics (PDF Card No. 00-034-0411).

\begin{tabular}{cccc}
\hline Crystal system & Cubic & Angles $(\alpha, \beta, \gamma)$ & $90.00^{\circ}, 90.00^{\circ}, 90.00^{\circ}$ \\
Space group number & 221 & Calculated density & 5.68 \\
Space group & Pm-3m & Volume of cell & 62.33 \\
Lattice parameter s & $3.965 \AA, 3.965 \AA, 3.965 \AA$ & & \\
\hline
\end{tabular}

Table 2. Details of the calculated X-ray spectrum for BST powder calcined at $750{ }^{\circ} \mathrm{C}$.

\begin{tabular}{|c|c|c|c|c|c|}
\hline h k l & $2 \theta[\mathrm{deg}]$ & $\mathrm{d}_{\mathrm{hkl}}[\AA]$ & FWHM [deg] & Crystal size $[\mathrm{nm}]$ & Lattice parameter $[\AA]$ \\
\hline 100 & 22.265 & 3.9893 & 0.1993 & 40.61 & \\
\hline 110 & 31.827 & 2.8092 & 0.2423 & 34.08 & \\
\hline 111 & 39.368 & 2.2867 & 0.2709 & 31.13 & \\
\hline \multirow[t]{2}{*}{200} & 45.724 & 1.9826 & 0.3145 & 27.40 & \\
\hline & & & Average & 33.31 & \\
\hline 310 & 75.897 & 1.2525 & & & 3.959 \\
\hline 311 & 80.035 & 1.1979 & & & 3.971 \\
\hline \multirow[t]{2}{*}{222} & 84.608 & 1.1444 & & & 3.963 \\
\hline & & & & Average & 3.965 \\
\hline
\end{tabular}

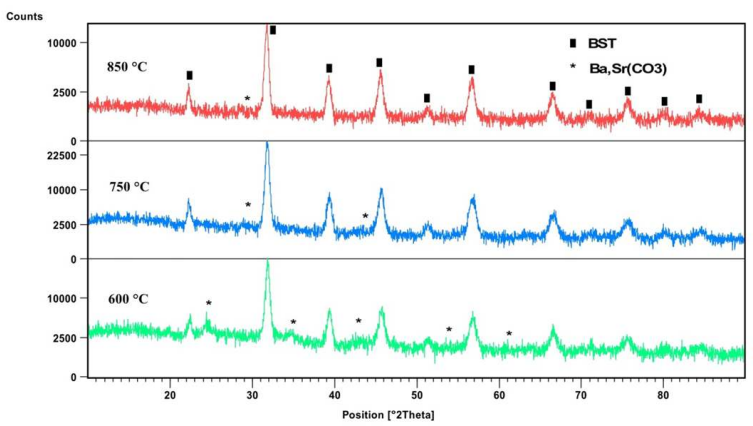

Fig. 4. XRD patterns of the BST powders synthesized at $600,750,850{ }^{\circ} \mathrm{C}$. The peaks associated with the barium carbonate secondary phases are marked with asterisks.

In order to determine the lattice constant, the equation for a cubic crystal was used:

$$
\sin ^{2} \theta=\lambda^{2}\left(h^{2}+k^{2}+l^{2}\right) / 4 a^{2}
$$

where $\mathrm{a}$ is the lattice spacing of a cubic crystal, and $\mathrm{h} \mathrm{k} \mathrm{l}$ are the Miller indices of the Bragg plane.

Table 2 and Table 3 show details of the calculated X-ray spectrum for the BST powder calcined at $750{ }^{\circ} \mathrm{C}$ and $850{ }^{\circ} \mathrm{C}$. The average crystallite sizes of the samples, calculated using Scherrer's formula for the first four predominant peaks were $33 \mathrm{~nm}$. When the calcination temperature was raised from 750 to $850{ }^{\circ} \mathrm{C}$, the average crystallite sizes increased and achieved $38 \mathrm{~nm}$. The lattice constant was calculated for the final three peaks for larger angles, because $a$ depends on $\sin \theta$ and at high values of $\theta$ the error in the calculated $\sin \theta$ value is reduced. This leads to a smaller error in the calculated value of the lattice parameter. The calculated lattice parameter (a) is in good agreement with the result of the X-ray pattern fitting for BST60/40 ceramics as shown in Table 1.

\subsection{FESEM and EDS analyses}

Fig. 5 shows the surface morphologies obtained using field emission scanning electron microscope (FESEM) at high magnifications. BST powder samples calcined for 2 hours at $750{ }^{\circ} \mathrm{C}$ and 4 hours for $850{ }^{\circ} \mathrm{C}$ are illustrated in Fig. 5a and 5b, respectively. The particles are nearly cubic in nature and less agglomerated, and they show welldistributed crystallites and dense nanoparticles surfaces. The images in Fig. 5a and 5b show an increase in grain growth with increasing calcination temperature from $750{ }^{\circ} \mathrm{C}$ to $850{ }^{\circ} \mathrm{C}$. The image in 
Table 3. Details of the calculated X-ray spectrum for BST powder calcined at $850{ }^{\circ} \mathrm{C}$.

\begin{tabular}{|c|c|c|c|c|c|}
\hline $\mathrm{h} \mathrm{k} \mathrm{l}$ & $2 \theta[\mathrm{deg}]$ & $\mathrm{d}_{\mathrm{hkl}}[\AA]$ & FWHM [deg] & Crystal size $[\mathrm{nm}]$ & Lattice parameter $[\AA]$ \\
\hline 100 & 22.279 & 3.9869 & 0.1665 & 48.61 & \\
\hline 110 & 31.826 & 2.8093 & 0.2193 & 37.65 & \\
\hline 111 & 39.312 & 2.2899 & 0.253 & 33.33 & \\
\hline \multirow[t]{2}{*}{200} & 45.632 & 1.9864 & 0.2748 & 31.35 & \\
\hline & & & Average & 37.74 & \\
\hline 310 & 75.609 & 1.2566 & & & 3.972 \\
\hline 311 & 80.281 & 1.1948 & & & 3.961 \\
\hline \multirow[t]{2}{*}{222} & 84.378 & 1.1469 & & & 3.972 \\
\hline & & & & Average & 3.969 \\
\hline
\end{tabular}

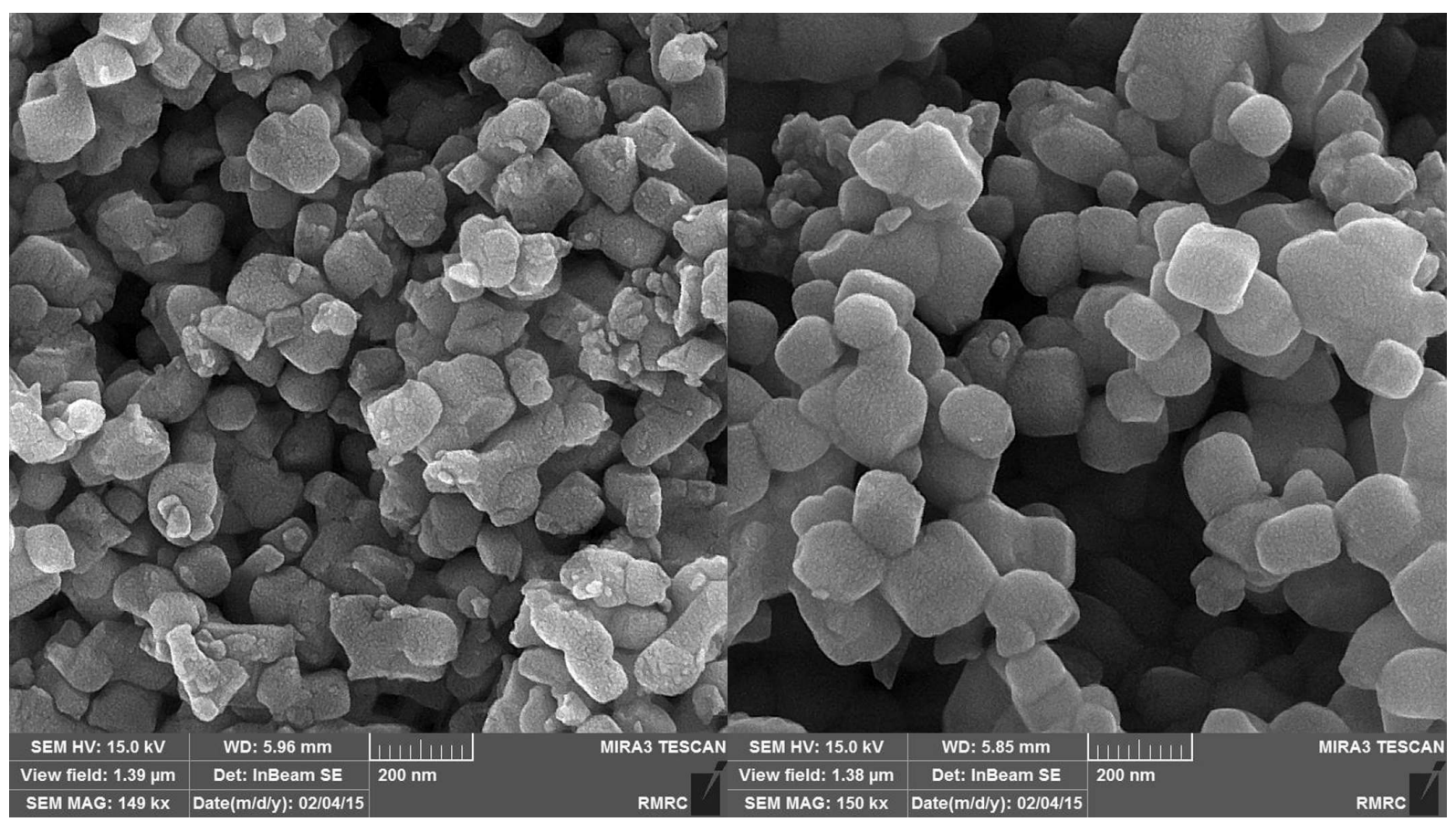

(a)

(b)

Fig. 5. The FESEM micrograph of BST (a) calcined at $750{ }^{\circ} \mathrm{C}$ for $2 \mathrm{~h}$ and (b) calcined at $850{ }^{\circ} \mathrm{C}$ for $4 \mathrm{~h}$.

Fig. $5 \mathrm{~b}$ shows that the structure of the particles calcined at $850^{\circ} \mathrm{C}$ is more crystalline and the particles are nearly of cubic shape. The result is consistent with the results of XRD and FT-IR analyses of the prepared samples.

Fig. 6 shows the EDS spectra of $\mathrm{Ba}_{0.6} \mathrm{Sr}_{0.4} \mathrm{TiO}_{3}$ (BST60/40) calcined at $750{ }^{\circ} \mathrm{C}$ for $2 \mathrm{~h}$. As can be seen, the presence of $\mathrm{Ba}, \mathrm{Sr}$, Ti and $\mathrm{O}$ was detected in the spectra. The results confirm that pure BST is a dominant phase. Furthermore, the composition ratio $(\mathrm{Ba} / \mathrm{Sr})$ of the as prepared powder was confirmed using the microarea EDS analysis. Stoichiometric ratios of the main metallic components of the BST60/40 ceramics are as follows (in mass \%): $\mathrm{Ba}-38.64 \%, \mathrm{Sr}-16.43 \%, \mathrm{Ti}-22.44 \%$. The results of the measurement, given in Fig. 6, are in acceptable agreement with the stoichiometric ratios mentioned above. Thus, the conservation of the chemical composition of the BST60/40 ceramics 
was proved and the accuracy higher than $\pm 5 \%$ was found.

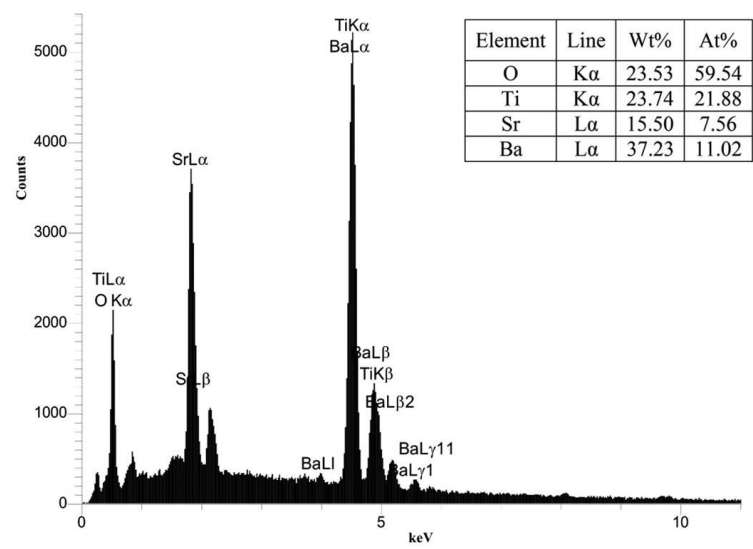

Fig. 6. The EDS pattern of the $\mathrm{Ba}_{0.6} \mathrm{Sr}_{0.4} \mathrm{TiO}_{3}$ powder synthesized at $750{ }^{\circ} \mathrm{C}$.

\section{Conclusion}

Nanocrystalline $\mathrm{Ba}_{0.6} \mathrm{Sr}_{0.4} \mathrm{TiO}_{3}$ powder has been successfully synthesized by a modified sol-gel technique. XRD patterns confirmed the cubic structure of the prepared samples. XRD and FT-IR analyses revealed that pure phase BST can be obtained above $750{ }^{\circ} \mathrm{C}$. The average of particle size calculated from the XRD pattern was 33 and $37 \mathrm{~nm}$ for calcination temperatures 750 and $850{ }^{\circ} \mathrm{C}$, respectively. The lattice parameter was found to be nearly $3.965 \AA$ based on Brag's formula. FESEM investigation showed that the nanoparticles obtained at $850{ }^{\circ} \mathrm{C}$ were more agglomerated and larger in size than those obtained at $750{ }^{\circ} \mathrm{C}$. The sol-gel process developed in this research can be used to deposit nano-thin films of BST for the applications in tunable ferroelectric devices.

\section{References}

[1] JANG H., Jun Y.H., Ferroelectrics, 193 (1997), 125.

[2] WodeckA-Duś B., LisińsKA-CZEKAJ A., ORKISZ T., AdAmczyk M., Osińska K., Mater. Sci.Poland, 25 (2007), 791.
[3] Maitra S., Banerjee M., Mukherjee S., Singh P.K., J. Aust. Ceram. Soc., 49 (2013), 79.

[4] Gomez-YanÄez C., Benitez C., BAlmoriRAMirez H., Ceram. Int., 26 (2000), 271.

[5] Ahmed M.A, Kamal M., El Desouky F.G., GiRGis E., Farag I.S.A., BattTisha I.K., J. Appl. Sci. Res., 9 (2013), 2432.

[6] Enhessari M., Parviz A., Ozaee K., Habibi Abyaneh H., Int. J. Nano Dimens., 2 (2011), 85.

[7] Somani V., Jyoti Kalita S., J. Electroceram., 18 (2007), 57.

[8] Simoesa A.Z., MouraA F., OnOfreA T.B., Ramirezc M.A., VArelaC J.A., LONGOC E., J. Alloy. Compd., 508 (2010), 620.

[9] Thakur O.P., Prakash C., Agrawal D.K., Mater. Lett., 56 (2002), 970.

[10] Golego N., Studenikin S.A., Cocivera M., Chem. Mater. 10 (1998), 2000.

[11] Zhong Z., Gallagher P.K., J. Mater. Res., 10 (1995), 942.

[12] Schrey F., J. Am. Ceram. Soc., 48 (1965), 401.

[13] Kocanda M., Mohiudin S.F., Abdel-Motaleb I.B., CSTA, 1 (2012), 17.

[14] Reynolds Glyn J., Kratzer M., Dubs M., Felzer H., Mamazza R., Materials, 5 (2012), 575.

[15] Jiquan H., Maochun H., Feilong J., Yongge C., Mater. Lett., 62 (2008), 2304.

[16] Du J., Choy K.L., Mat. Sci. Eng. C, 26 (2006), 1117.

[17] Harizanov O., Harizanova A., Mater. Sci. Eng. B, 106 (2004), 191.

[18] Brinker C., Hurd A.J., J. Non-Cryst. Solids., 147 (1992), 424.

[19] Golmohammad M., Nemati Z.A, Faghini Sani M.A., Mater. Sci.-Poland, 28 (2010), 421.

[20] Bellamy L.J., The Infra-red Spectra of Complex Molecules, Methuen., London, 1958.

[21] Duran P., Capel F., Gutierrez D., Tartaj J., BANARes M.A., Moure C., J. Mater. Chem., 11 (2001), 1828.

[22] Tangwiwat S., Milne S.J., J. Non-Cryst. Solids, 351 (2005), 976.

[23] Burgos M., Langlet M., Thin Solid Films, 349 (1999), 19.

[24] Miller F.A.,Wilkins C.H., Anal. Chem., 24 (8) (1952), 1253.

[25] Kao C.F, Yang W.D., Appl. Organomet. Chem., 13 (1999), 383. 